\title{
O lúdico no processo pedagógico da educação infantil: importante, porém ausente
}

\author{
Liana Romera* \\ Cristina Russo, Regiane E. Bueno, Adriana Padovani, \\ Ana Paula C. Silva, Camila R. da Silva, Gisele de Abreu \\ Íris Bini, Priscila B. Campos, Patrícia Duarte da Silva**
}

\begin{abstract}
Resumo: Este estudo observou e analisou a presença do lúdico no fazer educacional das professoras das escolas infantis das redes pública e particular da cidade de São José do Rio Preto. Por meio de pesquisas bibliográfica e empírica, foram abordadas escolas distribuídas nos quatro setores da cidade, nas quais se realizou, primeiramente, uma observação sistematizada e posteriormente a aplicação de um questionário junto às professoras. O principal objetivo foi verificar se no cotidiano escolar das unidades de ensino infantil envolvidas na pesquisa havia ou não situações de utilização de atividades lúdicas, planejamento das atividades ou seu uso aleatório, assim como a compreensão das professoras acerca do brincar na educação infantil. Os dados coletados foram tratados de modo comparativo entre os dois modelos de escolas compreendidas nos setores público e privado, o que possibilitou traçar um percurso do lúdico na educação infantil e no fazer pedagógico das professoras que, na época, atuavam nos distintos segmentos com a respectiva faixa etária.
\end{abstract}

Palavras-chave: Jogos e brinquedos. Aprendizagem. Educação infantil. Planejamento.

\section{INTRODUÇÃO}

O lúdico tem se apresentado como uma temática de bastante destaque nos encontros, congressos e eventos na área educacional, assim como nos discursos educacionais, observando-se também um crescente número de publicações enfocando o tema. Exaltado por suas possibilidades e contribuições no desenvolvimento dos domínios cognitivo, afetivo e motor da criança, vem apresentando-se como

* Doutoranda da Faculdade de Educação Física da Universidade Estadual de Campinas (FEF-UNICAMP) e Professora da Escola Superior de Educação Física da União das Faculdades Integradas da Fundação Padre Albino (ESEFIC/UNIFIPA). E-mail: liromera@uol.com.br

** Alunas do curso de Pedagogia da UNICERES São José do Rio Preto. 
uma temática de bastante interesse e aprofundamento em termos de pesquisa e aplicação, principalmente na área educacional.

Nesse sentido, o interesse do presente estudo está voltado para o dia-a-dia das escolas e as relações que se estabelecem entre estas e a aplicabilidade das atividades lúdicas. Elas ocorrem de fato? Qual a compreensão que se tem sobre o que seja atividade lúdica? Essas atividades encontram-se vinculadas ao processo de ensino/ aprendizagem?

Buscando respostas para as indagações apresentadas, verificouse, no cotidiano escolar das unidades de ensino infantil pesquisadas, a ocorrência e utilização de atividades lúdicas ou sua ausência, planejamento dessas atividades ou seu uso aleatório, buscando compreender qual o entendimento que as professoras que atuam com a faixa etária aqui explicitada apresentam acerca do assunto.

Na pesquisa bibliográfica, objetivou-se um aprofundamento da compreensão do lúdico, a partir das diferentes correntes que o enfocam e seu emprego na educação. Para tanto, foi realizado um levantamento bibliográfico, através do qual foram estudados os autores que se debruçam sobre o tema, conferindo às alunas do grupo de iniciação científica um maior entendimento das questões que o permeiam, para que, a partir dessa compreensão, obtivessem mais subsídios para observação e análise da aplicação do lúdico nas escolas envolvidas na pesquisa.

Na segunda fase, foram realizadas vinte horas de observação não-participante, desenvolvida na forma de estágio, uma vez que as escolas analisadas na pesquisa eram as mesmas de realização do estágio supervisionado das referidas alunas.

Portanto, as horas de observação dos estágios forneceram subsídios para as análises sobre a aplicação do lúdico por parte das professoras com as quais estagiavam e, num segundo momento, aplicaram a entrevista semi-estruturada, através de um instrumento composto de cinco questões.

Foram 12 as escolas analisadas por este estudo, compreendendo oito escolas da rede pública municipal, três escolas da rede particular,

Movimento, Porto Alegre, v.13, n. 02, p.131-152, maio/agosto de 2007. 
todas em São José do Rio Preto, e uma escola da rede particular da cidade de Nova Granada, no estado de São Paulo, Brasil. Entretanto, para fins de leitura e comparação dos dados coletados, achou-se por bem fazê-lo separadamente, respeitando-se uma linha divisória entre o ensino público e o particular devido às diferenças de realidades vivenciadas pelos protagonistas dos distintos segmentos.

Durante as vinte horas de observação, as alunas colheram informações acerca do emprego do lúdico por parte da professora, podendo verificar quando este era empregado, qual o objetivo de sua utilização, por quanto tempo e com quais intenções de uso. Todas as informações obtidas durante as horas de observação foram anotadas em uma ficha de observação padronizada do diário de campo.

No segundo momento da pesquisa de campo, as alunas de iniciação científica solicitaram à professora, junto à qual estagiavam, que respondesse a um questionário composto por cinco questões abertas, todas relacionadas à aplicação do lúdico no processo educacional no qual atuavam.

Os principais objetivos da pesquisa bibliográfica foram:

- compreender as conceituações do termo "lúdico", as correntes teóricas que o sustentam e os autores que buscam aprofundar o assunto, fazendo deste seu objeto de estudo. Ao fazer uso da pesquisa empírica, objetivou-se, por meio de seus instrumentos de coleta dos dados;

- conhecer qual o emprego do lúdico no cotidiano escolar da educação infantil a partir da verificação das atividades desenvolvidas, levando em conta: regularidade da aplicação, sistematização, planejamento das atividades e sua intensidade .

- perceber junto às professoras entrevistadas qual compreensão e conceito elas apresentavam sobre o termo, além do entendimento de seu alcance na educação do público infantil;

- descobrir junto às professoras pesquisadas a presença de disciplinas que, durante o período de formação acadêmica, abordassem a temática lúdica e lhes fornecessem subsídios para sua compreensão e utilização em sala de aula.

Movimento, Porto Alegre, v.13, n. 02, p.131-152, maio/agosto de 2007. 
- perceber junto às professoras pesquisadas se, nas atividades de caráter pedagógico por elas desenvolvidas, é possível constatar a presença de algum objetivo nas atividades lúdicas aplicadas, ou se seu uso era aleatório e não planejado.

A partir dos dados colhidos, pôde-se, então, analisar as formas de aplicação do lúdico tanto nas escolas infantis da rede pública municipal quanto naquelas que representam o ensino privado para posteriormente compará-los, contribuindo, assim, dentro dos limites que a pesquisa encerra, para a expansão da compreensão do emprego do lúdico no ensino infantil da cidade de São José do Rio Preto.

\section{METODOLOGIA}

A metodologia empregada para a realização deste estudo valeu-se da combinação das pesquisas bibliográfica e empírica.

O levantamento bibliográfico objetivando o embasamento teórico das discussões esteve condicionado à conceituação dos principais termos empregados na pesquisa, compreendidos a partir da visão dos autores que se destacam nos estudos concernentes ao lúdico.

A pesquisa empírica foi desenvolvida em dois momentos distintos e complementares: no primeiro momento, o grupo de alunas de iniciação científica realizou vinte horas de observação em escolas infantis da cidade de São José do Rio Preto e no segundo momento aplicou os questionários junto às professoras anteriormente observadas durante o desempenho de suas funções educacionais. Para as referidas coletas de dados, foram utilizadas as técnicas da observação não-participante com diário de campo, conforme Lakatos e Marconi (1991), seguidas da aplicação de entrevista semiestruturada.

Durante as observações não-participantes, assim como na aplicação das entrevistas, objetivou-se perceber a presença ou ausência de atividades lúdicas, o tempo de duração dessas atividades, o planejamento e a possível relação com outros conteúdos, o envolvimento ativo ou passivo da professora, além do levantamento acerca da compreensão, conhecimento e grau de importância atribuída

Movimento, Porto Alegre, v.13, n. 02, p.131-152, maio/agosto de 2007. 
ao lúdico no processo educacional apresentado por cada professora entrevistada.

O critério de escolha das escolas deu-se primeiramente respeitando a representatividade dos quatro setores regionais e administrativos da cidade, compreendidos pelas zonas norte, sul, leste e oeste, seguido de critério de acessibilidade por parte das alunas envolvidas na pesquisa, sendo essa amostragem composta por 12 escolas infantis das redes pública e privada de ensino.

Devido às diferentes realidades observadas no cotidiano dessas escolas, optou-se por uma análise separada dos segmentos em questão, seguida de um estudo comparativo entre eles, imprimindo maior fidedignidade às discussões assim como aos resultados apresentados neste estudo.

\subsection{Desenvolvimento: o lúdico e a educação}

A vinculação do termo "lúdico" à educação tem sido constante nos discursos da área pedagógica, na qual a exaltação de sua importância, a valorização de seu emprego para o desenvolvimento integral da criança ressoa por toda parte. Apesar do destaque mais intenso que o tema vem recebendo atualmente, os estudos que defendem sua aplicação e seu vínculo ao processo educativo podem ser verificados ao longo dos registros de nossa história. Diversos são os autores que desde a Antigüidade ressaltam as qualidades educativas que o jogo, por seus atributos, tem a propriedade de alcançar.

Conforme afirma Kishimoto (1998), a importância do jogo já fora destacada por filósofos como Platão e Aristóteles, e posteriormente Quintiliano, Montaigne e Rousseau, que já defendiam, àquela época, o papel do jogo na educação. No entanto, afirma a autora que foi no início do século passado, a partir de Fröebel (1913), o criador do jardim-dainfância, que o jogo passou a fazer parte do currículo de educação infantil.

Desde a Antigüidade, destaca-se como grande defensor das atividades lúdicas São Tomás de Aquino, que, no século XIII, defendia o brincar como necessário para o desenvolvimento humano.

A partir da década de cinqüenta do século XX, surgiram vários

Movimento, Porto Alegre, v.13, n. 02, p.131-152, maio/agosto de 2007. 


\section{Artigos Originais}

estudos sobre o jogo, e seus mais importantes estudiosos concordam ser ele um fenômeno da mente, sendo visto como uma atividade que pode ser expressiva ou geradora de habilidades cognitivas gerais.

Destacam-se obras de outros autores que se debruçaram sobre o tema, como Callois (1988) e Huizinga (2000), que se propõem a um estudo do lúdico relacionando-o ao jogo. No entanto, são autores da psicologia, como Wallon (1966), Piaget (1978), Winnicott (1975), Vigotsky (1982), os principais autores que mostraram, a partir de suas obras, a importância do jogo como elemento de contribuição para o desenvolvimento infantil, proporcionando à criança a possibilidade de aquisição de regras, expressão de seu imaginário, apropriação e exploração do meio e aquisição de conhecimentos.

Segundo Huizinga (2000, p. 6),o lúdico manifesta-se através do jogo: "A existência do jogo é inegável. É possível negar, se se quiser, quase todas as abstrações: a justiça, a beleza, a verdade, o bem, Deus. É possível negar-se a seriedade, mas não o jogo". Defende o autor a "não seriedade do jogo", o que não significa afirmar que o jogo não é sério.

Vivemos, na atualidade, numa sociedade mais propensa ao Homo faber que ao Homo ludens; o brincar das crianças não é o que existe de mais importante no elenco de preocupações que os adultos têm com relação a elas, ou de expectativas que criam acerca de suas vivências escolares.

As observações colhidas durante a pesquisa de campo mostraram que, na escola infantil, em alguns casos, os pais são os primeiros a expressar insatisfação quando da percepção de que a criança tenha brincado durante o período de aula. Eles expressam uma satisfação maior com as tarefas e os trabalhos que possam ser desenvolvidos pelas crianças do que com as manifestações advindas dos jogos, das brincadeiras ou das atividades nas quais as manifestações lúdicas se encontram mais presentes, uma vez que, de certa maneira, situações permeadas de ludicidade não lhes soam como produtivas, tampouco como ferramenta de preparação de seus filhos para o futuro. A partir dessa forma de compreensão, o brincar é compreendido, na sociedade, como perda de tempo.

Movimento, Porto Alegre, v.13, n. 02, p.131-152, maio/agosto de 2007. 
Segundo Dohme (2003, p. 11): "Separar o aprender do brincar tem a anuência da maioria dos pais, sendo que alguns se afligem quando seus filhos trazem para casa indícios de que brincaram na escola, sem se preocuparem em procurar saber se isto foi uma estratégia de ensino, ou prazeroso na vivência da criança".

Para esses pais, o aprendizado assim como o desenvolvimento das crianças devem estar vinculados a um fazer incessante, por meio do qual a criança execute intermináveis tarefas, tendo o caderno repleto de exercícios e atividades, o que lhes proporciona, de certa forma, uma sensação de tranqüilidade com relação à formação educacional dos filhos.

Quando compara o furto do lúdico na infância e coloca as crianças das diferentes camadas sociais em níveis de igualdade, Marcellino (1990) denuncia a relação de dominação que existe entre as diferentes faixas etárias. Ao tratar do componente lúdico da cultura da criança, o autor defende a necessidade de este ser vivenciado, independentemente da classe social à qual a criança pertença.

Quando detecta a impossibilidade de vivência do lúdico nas diferentes camadas sociais, o autor alerta para a unidade de infância, mesmo reconhecendo suas diferenças de classe, porém levando em conta que "[...] com relação ao adulto, todas crianças são proletárias em termos de projeto humano, e da própria vivência de sua faixa etária" (MARCELLINO, 1990, p. 56).

Esse é um reflexo do mundo do trabalho, dentro do qual se deve sempre estar ocupado, produzindo algo, para assim ser útil na sociedade; é a confirmação do Homo faber, que consegue igualar crianças de diferentes meios socioeconômicos.

\subsection{0 jogo e as palavras}

O termo "lúdico" tem sua conceituação bastante imprecisa devido às múltiplas ações que designa: na língua portuguesa, apresenta mais de dez sinônimos que o acompanham, deixando observar a imprecisão que o vocábulo encerra, além das múltiplas abrangências que sua manifestação suscita. Num esforço para conceituar o termo, Marcellino ressalta:

Movimento, Porto Alegre, v.13, n. 02, p.131-152, maio/agosto de 2007. 
Percorrer os verbetes dos dicionários na busca do significado do lúdico é uma experiência interessante, mas pouco esclarecedora, sobretudo se for considerado que a tarefa de especificar um conceito implica na restrição do uso das palavras a ele relacionada. (1990, p. 24)

Huizinga, ressaltando as características do jogo, a partir das quais o lúdico se manifesta, assim conceitua o termo:

\begin{abstract}
[...] uma atividade livre, conscientemente tomada como "não séria" e exterior à vida habitual, mas ao mesmo tempo capaz de absorver o jogador de maneira intensa e total. É uma atividade desligada de todo e qualquer interesse material, com a qual não se pode obter qualquer lucro, praticada dentro de limites espaciais e temporais próprios, segundo uma certa ordem e certas regras. (HUIZINGA, 2000, p. 16).
\end{abstract}

O autor delega ao jogo o espaço de manifestação do componente lúdico da cultura e considera que de sua vivência não deve haver outra expectativa senão a do jogo pelo jogo, destituindo-o de qualquer possibilidade de instrumentalização.

Nesse sentido, a partir da compreensão de "lúdico" defendida por Huizinga (2000), observa-se que ele deve ter caráter espontâneo e desvinculado de um fazer produtivo, não cabendo, portanto, sua aplicação na escola com fins didáticos e pedagógicos, uma vez que, ao menos teoricamente, esses fins remetem à obtenção de alguns objetivos propostos segundo o professor que o utiliza como instrumento de aprendizagem, visando ao desenvolvimento de seus alunos no que se relaciona com o conteúdo ali aplicado.

Ao observarmos a fala das professoras, notamos o uso indistinto de alguns termos diretamente relacionados ao lúdico, tais como "jogo", "brinquedo" e "brincadeira" empregados em suas ações. Há uma diferenciação relativa a alguns termos que em muitas obras aparecem como sinônimos, mas que carregam em seu cerne certa distinção: os termos "jogo", "brinquedo" e "brincadeira" serão aqui conceituados a partir do estudo de Kishimoto (1998), que apre senta algumas peculiaridades a cada um deles, o que os torna dife rentes uns dos outros. A palavra "jogo", segundo a autora, pode ser

Movimento, Porto Alegre, v.13, n. 02, p.131-152, maio/agosto de 2007. 
identificada pela presença de um sistema de regras específicas, sendo também compreendido pelo próprio objeto, por exemplo: o tabuleiro de xadrez.

Já o brinquedo supõe uma relação íntima com a criança e uma indeterminação quanto ao uso, ou seja, não existe um sistema de regras que organize sua utilização. $\mathrm{O}$ brinquedo estimula a representação, a expressão de imagens que evocam aspectos da realidade. O brinquedo propõe, além do mais, um mundo imaginário da criança e do adulto, criador do objeto lúdico. O termo "brinquedo" não pode ser reduzido à pluralidade de sentidos do jogo, pois conota a criança e tem uma dimensão material, cultural e técnica. $\mathrm{O}$ brinquedo, sendo representado por um material, é sempre objeto suporte de uma brincadeira, exercendo a função de estimulante para fazer fluir o imaginário infantil. Nesse sentido, não tem o brinquedo a necessidade da industrialização, uma vez que, para a criatividade da criança, um cabo de vassoura se transforma em cavalo, um carretel amarrado a uma linha pode tornar-se um carrinho, uma espiga de milho vira boneca, que, aliás, é uma filhinha, é um bebê, e então já é gente. Por sua vez, a "brincadeira" representa a ação que a criança desempenha ao concretizar as regras do jogo, ao mergulhar na ação lúdica.

Brinquedo e brincadeira comunicam-se com a criança e não se confundem com jogo; no entanto, para a criança, são acompanhados da mesma seriedade que o vivenciar dessas atividades representa em suas vidas.

\subsection{As compreensões do jogo na educação}

Diante das discussões a respeito do jogo, representado pelo lúdico na educação, existem duas principais correntes que compreendem de modo antagônico sua empregabilidade no processo pedagógico. A primeira corrente defende uma função lúdica do jogo na qual ele propicia a diversão e tem um caráter essencialmente desinteressado. Nesta forma de abordagem do lúdico, a principal característica é o prazer proporcionado; ele deve ainda estar vinculado à livre adesão daquele que o pratica, não sendo permitido ao praticante visar qualquer possibilidade de produtividade.

Movimento, Porto Alegre, v.13, n. 02, p.131-152, maio/agosto de 2007. 
A segunda corrente trata de uma função educativa do lúdico: defende que o jogo ensina qualquer coisa que complete o indivíduo em seu saber, seus conhecimentos e sua apreensão do mundo, além de suscitar uma grande possibilidade de se constituir como elemento motivador do processo educacional.

Os autores que defendem a primeira corrente, para a qual o lúdico está diretamente relacionado à livre escolha e adesão, não comungam da idéia de sua utilização no campo pedagógico apresentada pela segunda corrente aqui explicitada. Para tanto, argumentam que o fato de se empregar o brinquedo com horário predeterminado, tendo um objetivo estabelecido a cumprir, visando a aspectos que não somente o do brincar por brincar, destitui da atividade particularidades que a caracterizam.

Os autores partidários da primeira corrente advertem sobre um aspecto importante a ser levado em conta: que o brinquedo não pode perder sua magia enquanto exerce função educativa, pois, a partir do momento em que deixa de provocar prazer e alegria em detrimento da aprendizagem, deixa de ser brinquedo e passa a ser tão-somente material pedagógico.

Já os autores defensores da segunda corrente de pensamento que envolve o tema defendem tratar-se de uma função educativa com propriedades bastante consideráveis a respeito do papel motivador que o jogo estabelece, podendo esta motivação ser direcionada ao campo da aprendizagem no sistema educacional, sendo, portanto, empregada como elemento facilitador e estimulador do processo de aprendizagem. Nessa segunda corrente, o jogo não se estabelece apenas pelo jogo, havendo uma intencionalidade que o acompanha.

Para Alain (1956, citado por KISHIMOTO, 1998, p. 21):

[...] existem dois momentos na situação escolar: o trabalho pedagógico de aquisição sistemática do saber e o jogo que, escapando à severa lei do trabalho, caminha em direção a um "não-sério", sem se submeter à ordem, criando um espaço de liberdade de ação para a criança.

Dessa forma, o autor defende a aplicação do jogo na educação.

Movimento, Porto Alegre, v.13, n. 02, p.131-152, maio/agosto de 2007. 
Segundo Kishimoto (1998) e Santos (2001), o equilíbrio entre as duas funções, lúdica e educativa, é o objetivo do jogo educativo, ressaltando ainda que a corrente que trata de uma função educativa defende que, através do jogo, se apresentam possibilidades de ensinar por meio de diferentes aspectos.

Esta compreensão acerca do emprego do jogo na educação também é defendida por Chateau (1987, citado por KISHIMOTO, 1998, p. 23), para quem deve haver uma estreita ligação entre o jogo o trabalho escolar.

Em síntese, Kishimoto (1998, p. 23) revela:

\begin{abstract}
Ao permitir a manifestação do imaginário infantil, por meio de objetos simbólicos dispostos intencionalmente, a função pedagógica subsidia o desenvolvimento integral da criança. Nesse sentido, qualquer jogo empregado pela escola, desde que respeite a natureza do ato lúdico, apresenta o caráter educativo e pode receber também a denominação geral de jogo educativo.
\end{abstract}

Advertindo sobre a importância de se respeitar a natureza do ato lúdico, a autora defende a aplicação do jogo no sistema educacional, de modo consciente, empregando-o ora como material que possibilite a livre exploração da criança, destituído de qualquer pragmatismo, ora como material que exige ações orientadas pelo professor. Dessa forma, ao estudar o lúdico manifesto por meio dos jogos no desenvolvimento da humanidade, os estudiosos de ambas as correntes ressaltadas reconhecem ser ele elemento motivador e instrumento de expressão tanto da cultura quanto da personalidade da criança.

Para contemplar os domínios sócio-afetivo, motor, cognitivo, os Parâmetros Curriculares Nacionais (PCNs) (1998) da educação infantil apontam as bases para que esses domínios específicos do desenvolvimento humano possam ser contemplados. Dentre essas, destaca-se "o direito da criança brincar, como forma particular de expressão, pensamento, interação e comunicação infantil" (PCNs, 1998, p. 13). Entendendo o referido documento como parâmetro das ações pedagógicas da educação infantil, espera-se, nos espaços de educação infantil, a presença do lúdico.

Movimento, Porto Alegre, v.13, n. 02, p.131-152, maio/agosto de 2007. 


\section{A PESQUISA EMPÍRICA}

Com relação aos modos de coleta dos dados a partir dos instrumentos estabelecidos para esse objetivo, tinha-se por meta, a princípio, uma entrevista presencial, na qual as entrevistadoras pudessem colher as informações necessárias diretamente com as professoras entrevistadas, por meio de gravadores. No entanto, a maior parte das professoras preferiu tomar a folha de perguntas e somente trazê-las respondidas em um próximo encontro com as alunas entrevistadoras.

Esse comportamento das professoras revelou certo grau de insegurança com relação à possibilidade de serem inquiridas sobre algo que lhes pudesse ser desconhecido e/ou com relação à temática do questionário; elas preferiram, então, não se expor à possibilidade de alguma incerteza ou desconhecimento relativo às perguntas. Desse modo, de um total de oito escolas que fazem parte da amostragem referente às escolas públicas da rede municipal aqui estudadas, em seis delas houve opção por parte das pro fessoras em responder às perguntas em outro momento, somente devolvendo a folha já preenchida. Das quatro professoras da rede particular, três optaram por não responder presencialmente às questões, também devolvendo a folha já preenchida posteriormente. Nesse aspecto, o comportamento das professoras tanto da rede municipal quanto da rede particular foi o mesmo, pois na sua quase totalidade foi observada a opção de não se expor de modo presencial.

\section{ANALISANDO AS RESPOSTAS}

A primeira questão do segundo instrumento de abordagem, representado por um questionário aberto e composto por cinco questões diretas, teve por objetivo levantar a compreensão que as professoras têm acerca do termo "lúdico?". "Qual o significado da palavra 'lúdico'?" Todas as professoras relacionaram o lúdico a jogos, brinquedos e brincadeiras, sem fazer nenhuma distinção entre os três termos, deixando transparecer uma associação do lúdico a momentos de descontração e prazer. Somente três professoras apresentaram uma relação entre o lúdico e a aprendizagem, ao responderam que o lúdico está relacionado ao "ensinar com

Movimento, Porto Alegre, v.13, n. 02, p.131-152, maio/agosto de 2007. 
brincadeiras" Na rede particular, ainda com relação à compreensão do lúdico, as professoras entrevistadas limitaram-se a classificar o lúdico como jogos, brinquedos e brincadeiras. Somente uma das professoras relacionou o lúdico a atividades de caráter prazeroso.

A segunda questão da entrevista referia-se à aplicação do lúdico em sala de aula por parte da professora seguido da solicitação de uma justificativa tanto para respostas positivas quanto para as negativas: "Você aplica o lúdico? Sim, de que maneira e quando? Não, por quê?".

Embora durante os relatos verbais e nos relatórios registrados nos diários de campo referentes às vinte horas de observação de algumas das alunas pesquisadoras tivesse havido apontamentos acerca das observações de sala de aula, as quais denunciavam a não aplicação de atividades lúdicas em nenhuma situação escolar privando assim os alunos de qualquer tipo de brincadeira, acesso a brinquedos, freqüência ao parquinho, dentre outras possibilidades de atividades lúdicas -, as professoras entrevistadas foram unânimes em afirmar a aplicação do lúdico, contemplando de maneira indistinta as duas correntes mencionadas que estudam o assunto, porém, sem apresentar qualquer conhecimento das discussões acadêmicas que o tema vem despertando junto a seus estudiosos.

Ao ressaltar a importância de tal atitude, deixam transparecer em suas respostas uma compreensão da importância do lúdico como instrumento de motivação para a aprendizagem assim como para um desenvolvimento integral da criança, por meio de brincadeiras direcionadas à aprendizagem de algum conteúdo específico, brincadeiras livres entre as crianças, resgate de brincadeiras populares (casinha, boneca, carrinho), encenação de historinhas, aplicação de jogos e brincadeiras, atividades livres, músicas, dinâmicas.

Importante ressaltar que, comparando essas respostas com aquelas apresentadas a respeito da primeira questão, se observa que mesmo não havendo, por parte das professoras, uma relação direta e significativa entre o brincar e o aprender, a partir de estratégias lúdicas de ensino/aprendizagem, as professoras destacaram, ao responder a segunda questão, um entendimento, mesmo que intuitivo, sobre a importância do lúdico, mas sem vinculá-lo

Movimento, Porto Alegre, v.13, n. 02, p.131-152, maio/agosto de 2007. 
diretamente às atividades pedagógicas por elas desenvolvidas com seus alunos. Pode-se concluir nesse aspecto uma desvinculação entre lúdico e aprendizagem, pois, a partir desse pensamento, o lúdico somente estará presente nas brincadeiras das crianças, e não na função de agente motivador do aprendizado.

As professoras da rede particular responderam à segunda questão também de forma positiva, expressando algumas delas não utilizar o lúdico na proporção desejada, mas sim naquela que lhes era possível, apontando o excesso de conteúdo a ser cumprido pelo programa de ensino como elemento impeditivo da aplicação de um volume maior de atividades lúdicas.

Esse excesso de atividades pedagógicas não lhes confere muito tempo para as brincadeiras, ressaltaram as professoras, podendo ser destacada, nessa afirmação, certa contrariedade com relação ao extenso conteúdo a ser desenvolvido. Mais uma vez pode-se observar a desvinculação existente entre o lúdico e a aquisição do conhecimento proposto por seus respectivos conteúdos programáticos.

Assim, pode-se concluir, a partir dessa questão, que o lúdico nas escolas particulares é compreendido na sua importância, porém, não muito aplicado em sala de aula, ou relacionado às suas possibilidades junto ao processo de facilitação da aprendizagem, assim como nos demais espaços que compõem o ambiente escolar: pátio, quadra esportiva, brinquedoteca, parquinho com atividades representadas por historinhas, encenação de personagens, teatro, entre outras. Quase não se percebe, por parte de algumas professoras, a vinculação desses espaços lúdicos com a possibilidade de aprendizagem de conteúdos.

Ao se destacar o caráter conteudista do ensino brasileiro, que contagiou até os espaços de educação infantil em nome de um preparar-se para o futuro, acaba-se subtraindo da criança oportunidades de brincar, sendo que tal situação é atribuída à escassez de tempo, que pouco resta após o cumprimento de todos os deveres.

A terceira questão do rol de perguntas do questionário aqui analisado se referia à formação do professor. Objetivou-se com

Movimento, Porto Alegre, v.13, n. 02, p.131-152, maio/agosto de 2007. 
esta questão refletir sobre a formação acadêmica: "O lúdico fez ou faz parte de sua formação acadêmica profissional?".

Em relação a essa questão houve uma pequena confusão por parte das professoras entrevistadas; embora a maioria delas tivesse respondido de modo afirmativo, elas não relacionaram o lúdico a alguma disciplina que tenham ou tivessem tido durante o período de formação na graduação. Preferiram direcionar a resposta para uma nova afirmação acerca da aplicação do lúdico junto aos seus alunos, referindo-se ao seu uso no dia-a-dia escolar.

As professoras das escolas particulares admitiram claramente que o lúdico não fez parte de sua formação, e que, durante sua vida acadêmica, ouviram muito pouco sobre o assunto; assim, tentam entender sobre o assunto por meio da literatura atual, deixando transparecer certo interesse e necessidade de desenvolver maior compreensão do tema.Observou-se por parte das professoras das escolas particulares um esforço pela busca do conhecimento, ao mesmo tempo em que se notou, por parte das professoras das escolas da rede pública municipal, uma dificuldade de admitir as próprias limitações, mesmo que estas não fossem de sua completa responsabilidade.

Chamamos a atenção, neste ponto, para um aspecto da formação das professoras: a grande maioria daquelas que se encontram hoje atuando tanto na rede pública quanto na particular são oriundas de uma época em que a legislação referente à educação exigia, para este exercício profissional, o curso técnico em nível de segundo grau, representado pelo Magistério, não havendo a exigência, para tanto, de curso de nível superior, conforme exigência da atual LDB.

A quarta questão do referido instrumento buscou compreender a visão que a direção da escola apresenta acerca do lúdico inserido no sistema educacional. Esta questão tem um caráter investigativo bastante importante para o presente estudo, pois entende que a partir da concepção de educação do gestor da escola é que se darão as diretrizes dela: "Como a direção e/ou coordenação da escola vêem o lúdico no sistema educacional?"

Com exceção de uma professora da rede municipal de ensino que não respondeu a esta questão, alegando não ter conhecimento

Movimento, Porto Alegre, v.13, n. 02, p.131-152, maio/agosto de 2007. 


\section{Astigor Originais}

Liana Romera, et al.

da visão da direção e coordenação da escola sobre o tema, todas as demais foram unânimes em ressaltar a importância que a direção da escola atribui ao lúdico, relacionando sua aplicação ao desenvolvimento da criança. Essa afirmação, mais uma vez, vem reforçar o entendimento que as professoras apresentam do assunto, pois até mesmo entre aquelas em que se constatou, durante o período de observação, a não utilização do lúdico em nenhuma circunstância, houve a afirmação de que a direção da escola não só aprova como incentiva a aplicação do lúdico, destacando-se ainda algumas comprovações científicas de sua utilização na educação.

Nas escolas da rede particular também foi observada uma compreensão positiva por parte da direção e coordenação, tanto na valorização quanto na estimulação de sua utilização. No entanto, destacam algumas que, mesmo tendo a direção da escola uma visão positiva sobre o lúdico, atribuem à sua vivência pouco tempo, uma vez que têm um extenso plano de ensino a cumprir.

A quinta e última questão, volta novamente, a focar a compreensão da importância do lúdico por parte da professora: "Que importância você atribui ao lúdico?". Novamente, houve grande ressonância entre as respostas; todas atribuíram ao lúdico grande importância, destacando as possibilidades que este tem como instrumento para o desenvolvimento infantil, para o relaxamento e, em escassas referências, como instrumento de auxílio no processo de alfabetização das crianças. $\mathrm{O}$ mesmo pode ser observado nas escolas da rede particular, notando-se ainda que desta vez complementam o conceito de lúdico de forma indireta, quando buscam justificar os diferentes empregos para ele.

\section{DISCUSSÕES}

De acordo com Marcellino (1990, p. 57), negar o lúdico é negar a esperança: "[...] o que se observa na nossa sociedade, com relação à criança é a impossibilidade de vivência do presente, em nome da preparação para um futuro que não lhe pertence".

Há, nesse caso, a desconsideração relativa à faixa etária, o que torna as denúncias mais sérias se ressaltarmos que o enfoque está direcionado a crianças passando pelo período da primeira

Movimento, Porto Alegre, v.13, n. 02, p.131-152, maio/agosto de 2007. 
infância, momento próprio, portanto, para que o lúdico, o brinquedo, a brincadeira aconteçam na maior parte do tempo.

Em nome de uma preparação para o futuro, no qual a criança deverá estar pronta para competir por uma vaga no mercado de trabalho, para o sucesso no mundo profissional, esta acaba tendo que abandonar, precocemente, seu tempo de brincar, ou, de modo inverso, quando a criança ainda não está preparada para o ingresso no mundo do trabalho e as contingências familiares e econômicas as empurram para trabalhos que exigem grandes esforços em troca de uma baixa remuneração. Em ambos os casos, verifica-se, conforme destacado por Marcellino (1990), a proletarização infantil. Segundo o autor, a escola tem contribuído bastante para essa situação, não deixando tempo suficiente para o brincar espontâneo das crianças, que desde muito cedo a freqüentam com o intuito de preparar-se para o futuro.

Nessa linha de pensamento, na qual a criança está sendo preparada para competir e atuar no mercado de trabalho, está subentendido que o brincar não é importante, tampouco necessário, pois não está vinculado à seriedade e à produtividade que marcam os tempos atuais. Preparar-se para as exigências do mercado de trabalho desde a primeira infância reflete o extenso conteúdo que esta faixa etária cumpre durante as aulas; em conseqüência, resta pouco tempo para brincar. Essa foi uma das denúncias das professoras entrevistadas que, embora compreendendo a importância do lúdico para o desenvolvimento da criança, lamentavam não haver tempo suficiente para sua vivência na escola, por conta do imenso conteúdo a cumprir.

Nesse sentido, fica-nos a indagação: que conteúdo será mais importante para a criança de 0 a 6 anos senão o próprio brincar? $\mathrm{Na}$ educação infantil, atualmente, as exigências são muito maiores para responder às demandas da educação da criança de 0 a 6 anos do que aquelas de tempos passados, quando a função da creche ou da escolinha se resumiam ao local para deixar a criança durante o período no qual seus pais ou responsáveis estivessem trabalhando. As escolas de educação infantil não são nada parecidas com depósitos de crianças, desprovidas dos objetivos de formação do cidadão, na

Movimento, Porto Alegre, v.13, n. 02, p.131-152, maio/agosto de 2007. 
busca de sua identidade e autonomia. Assim, exige-se do profissional de educação infantil, nos dias atuais, uma formação e um preparo muito maiores, o que na década passada não constava como necessário para o exercício do magistério.

Sendo assim, os PCNs (1998) devem ser considerados, principalmente quando propõem nas atividades permanentes como eixo dos componentes curriculares brincadeiras em espaço interno e externo, roda de história, ateliê ou oficinas de desenho, pintura, modelagem e música, o que leva o professor a ter a necessidade de diversificar suas aulas, porém, não se esquecendo do componente lúdico.

\section{CONSIDERAÇÕES FINAIS}

Conclui-se que, nas cidades pesquisadas, tanto entre as professoras da rede municipal de ensino infantil quanto para as professoras da rede particular, existe a compreensão sobre o lúdico e sua importância para a formação das crianças. No entanto, notou-se que há, dentro do mesmo sistema educacional, uma discrepância entre o fazer pedagógico de cada local, assim como com relação às atitudes pedagógicas, pois enquanto em algumas unidades se observou a aplicação do lúdico de modo intenso e criativo, em outras foi constatada sua total ausência. Dessa forma, a aplicação do lúdico na educação parece depender muito de cada professora, posto que cada uma trabalha com suas crianças de modo particular. Dentre as unidades em que se constatou o trabalho com o lúdico, pode ser observado seu planejamento prévio. Tal planejamento fica mais explícito nas escolas particulares, que têm dia e horário definido para cada atividade.

Embora estudos que pudessem enfocar o lúdico não tenham feito parte da formação acadêmica de muitas das professoras entrevistadas, viu-se nelas um esforço por afirmar sua aplicação. No entanto, nem todas as afirmações a respeito da aplicação do lúdico presentes nas entrevistas puderam ser verificadas, de fato, durante as horas de observação realizada anteriormente à aplicação do questionário.

Movimento, Porto Alegre, v.13, n. 02, p.131-152, maio/agosto de 2007. 
Constataram-se, portanto, algumas contradições entre o falar e o fazer. Tal fato mostrou a independência do fazer pedagógico que permeia cada sala de aula. Verificou-se, também, certa angústia por parte das professoras no que se relaciona à quantidade de conteúdo a ser desenvolvido em sala de aula, o que lhes subtrai uma grande parte do tempo que, segundo elas, poderia ser direcionado a atividades lúdicas. Observou-se aqui a escassa relação que se faz interligando o lúdico com as atividades programadas, pois algumas das professoras entrevistadas nos levaram a entender que, para que o lúdico aconteça, as atividades do programa têm que cessar, sem supor uma simultaneidade de ações, lúdicas e pedagógicas. Com relação às discussões acerca das correntes teóricas que permeiam o tema, em nenhum momento as entrevistadas mostraram conhecer ou ser partidárias de alguma das distintas teorias do lúdico apresentadas no início deste trabalho.

Outra questão observada foi a classificação das atividades lúdicas pelas professoras, pois algumas delas as aplicavam em suas aulas sem saber, o que vem corroborar as afirmações de Kishimoto (1998).

Transpareceram também algumas incertezas por parte das professoras, justificável pela ausência de um estudo sistematizado do assunto durante seu processo de formação; elas têm conhecimento da importância do lúdico no desenvolvimento da criança, têm o aval da direção e coordenação da escola para sua utilização, porém poucos foram, por exemplo, os momentos que se utilizaram de outro espaço escolar que não fosse a sala de aula e o parquinho. Notou-se a dificuldade em relacionar as atividades lúdicas ao desenvolvimento dos conteúdos a serem cumpridos, o que demonstra uma visão fragmentada do lúdico. Tal fato se justifica novamente pela ausência de práticas, vivências e discussões do tema durante o período de formação.

Dessa forma, encerramos a presente pesquisa concluindo que o lúdico é conhecido dos profissionais que atuam na área da educação infantil, há unanimidade no reconhecimento de sua importância para o desenvolvimento da criança, assim como da necessidade que esta tem de vivenciá-lo; no entanto, sua aplicação de modo amplo ainda não é observada na prática de maneira intensa, como

Movimento, Porto Alegre, v.13, n. 02, p.131-152, maio/agosto de 2007. 


\section{Artigos Originais}

Liana Romera, et al.

se poderia supor que ocorresse na educação infantil, período da infância ao menos teoricamente reservado para o brincar. Embora em muitos casos as professoras tenham demonstrado o desejo de ter mais tempo para as atividades lúdicas, a realidade estabelecida lhes dificulta a aplicação, seja pelo caráter conteudista de nosso modelo de ensino, seja pelo número excessivo de crianças por sala de aula. Nota-se nas professoras a necessidade de maiores esclarecimentos acerca do lúdico e de sua associação ao processo de ensino/aprendizagem, destacando as possibilidades de relação entre o lúdico e a aquisição de conhecimento, podendo dar a este um aspecto significativo e prazeroso.

Nas escolas da rede privada de ensino, constatou-se com maior facilidade a presença do lúdico, ao passo que se verificou entre as escolas públicas da rede municipal de ensino realidades bastante distintas, o que não nos dá parâmetros para comparação entre o público e o privado.

Movimento, Porto Alegre, v.13, n. 02, p.131-152, maio/agosto de 2007. 
The playful in the pedagogic process of infantile education: important but absent Abstract: This study observed and analyzed the presence of playful teaching practice on the educational action of teachers in the kindergarten school both from the public and private sectors in the city of São José do Rio Preto. By means of a bibliographical and empirical research, schools from four different parts of the city were evaluated and systematically observed. Later, a questionnaire was applied to the teachers. The main objective was to verify whether or not there were situations in which playful activities would be part of the teacher's daily agenda, either as a planned activity or even used randomly, as well as the understanding of the teachers concerning this matter in the infantile education.

Keywords: Play and playthings. Learning. Child rearing. Planning.

El lúdico en el process pedagógico de la educación infantil: importante pero ausente.

Resumen: Este estudio analisó la presencia del juguete en el hacer pedagógico de las maestras en guarderías de la red pública de la ciudad de São José do Rio Preto. Por medio de encuestas bibliográficas y empíricas, fueran abordadas escuelas distribuidas en los cuatro sectores de la ciudad en los cuales se realizó una observación sistematizada, y después la aplicación de una encuesta con los maestros. El objectivo primero fue verificar si en el cotidiano de las escuelas tenía o no situaciones de utilización de actividades lúdicas, planeamento de las actividades o empleo obligatorio, como también la comprensión de las mismas acerca de los juguetes infantiles.

Palabras clave: Juego y implementos del juego. Aprendizaje. Crianza del niño. Planificación.

\section{REFERÊNCIAS}

BRASIL. Ministério da Educação e do Desporto. Secretaria de Educação Fundamental. Parâmetros Curriculares Nacionais. Brasília, 1998.

CALLOIS, R. O homem e o sagrado. Lisboa, 1988 (Coleção Perspectivas do Homem).

DOHME, V. O valor educacional dos jogos. São Paulo: Informal, 2003.

Movimento, Porto Alegre, v.13, n. 02, p.131-152, maio/agosto de 2007. 
FRÖEBEL, F. La educación del hombre. Traducción del alemán por Luis del Zulueta. Madrid: Daniel Jorro, 1913.

HUIZINGA, J. Homo ludens. 4. ed. São Paulo: Perspectiva, 2000.

KISHIMOTO, T. M. O jogo e a educação infantil. São Paulo: Pioneira, 1998.

KISHIMOTO, T. M. (org.). Jogo, brinquedo, brincadeira e a educação. 5. ed. São Paulo: Cortez, 2001.

KISHIMOTO, T. M. (org.) O brincar e suas teorias. São Paulo: Pioneira, 2002.

LAKATOS, E. M.; MARCONI, M. A. Fundamentos de metodologia científica. 3. ed. São Paulo: Atlas, 1991.

LEI de Diretrizes e Bases da Educação Nacional: texto aprovado na Comissão de Educação, Cultura e Desporto da CD com comentários de Dermeval Saviani [et al.]. São Paulo: Cortez, ANDE, 1990.

MARCELLINO, N. C. Pedagogia da animação. Campinas: Papirus, 1990.

MARCELLINO, N. C. (org.). Lúdico, educação e educação física. ljuí: UNIJUÍ 1999.

PIAGET, J. A formação do símbolo na criança. Rio de Janeiro: Zahar, 1978.

SANTOS, S. M. P. (org.). A ludicidade como ciência. Petrópolis: Vozes, 2001.

VYGOTSKY, Lev, S. A formação social da mente. São Paulo: Martins Fontes, 1982.

WALLON, H. Do ato ao pensamento. Lisboa: Portugália Ed., 1966.

WINNICOTT, D. W. O brincar e a realidade. Rio de Janeiro: Imago,1975.

Movimento, Porto Alegre, v.13, n. 02, p.131-152, maio/agosto de 2007. 